\title{
Hemşire Liderliğinde Romatoid Artritli Hastalara Verilen Bakımın Etkinliği
}

\section{(Sistematik Derleme)}

Effectiveness of Maintenance Given to Romatoid Arthritis Disease in Nursing Leadership (Systematic Review)

Halil İbrahim TUNA ${ }^{1}$ Özlem ÖRSAL ${ }^{2}$

\section{ÖZ}

Geleneksel olarak tüm Romatoid Artrit (RA) hastalarının takip edilmesi, kliniklerde romatologlar tarafından gerçekleştirilir. Günümüzde romatoloji kliniklerindeki hemşireler, multidisipliner ekibin önemli bir parçası haline gelmektedir ve romatolojik görevleri gerçekleştirebilmektedir. Kliniklerde hemşire odaklı bakım ile hizmet alan hastalar; fiziksel işlev, hastalık aktivitesi, yaşam kalitesi, ağrı, yorgunluk, sertlik, psikolojik işlev ve memnuniyet açısından daha iyi sonuçlar almışlardır. $\mathrm{Bu}$ güncel sistematik derlemenin amacı, romatoid artritli hastalarda hemşire liderlikli hastalık yönetiminin klinik bakımdaki etkinliğinin belirlenmesidir. Derlemede bir üniversitenin kütüphane ağı üzerinden "romatoid artrit, hemşire ya da hemşirelik, sağlık bakımı" anahtar kelimeleri taranmıştır. Araştırmaya; 2008-2019 yılları arasinda Science Direct, PubMed, EBSCO Host, ULAKBİM, Türkiye Atıf Dizini veri tabanlarında yayınlanmış ücretsiz, tam metin makaleler dahil edilmiştir. Derlemede hemşire liderliğindeki RA kliniklerinin hasta bakım sonuçlarına etkisi olan makalelere yer verilmiştir. Derlemenin sonunda hemşire liderlikli bakım, beklenen tedavi sonuçlarını karşılamaktadır ve hastalar için oldukça güvenlidir sonucuna ulaşılmıştır.

Anahtar Kelimeler: Romatoid Artrit, Hemşirelik, Bakım, Sağlık Bakımı

\begin{abstract}
Traditionally all rheumatoid arthritis (RA) patients are followed by rheumatologists in clinics. Nowadays, nurses in rheumatology clinics become an importantpart of the multidisciplinary team and can perform rheumatological tasks. Nursing-based care in clinics; physical function, disease activity, quality of life, pain, fatigue, hardness, psychological function and satisfaction. The aim of this current systematic review is to determine the clinical effectiveness of nurse-led disease management in patients with rheumatoid arthritis. In this review, keywords "rheumatoid arthritis, nurse or nursing, healthcare" were scanned through the library network of a university. Research; Between the years 2008-2019 Science Direct, PubMed, EBSCO Host, ULAKBIM, published in Turkey free Citation Index database, full-text articles were included. The compiled nurse-led RA clinics include articles that affect patient care outcomes. Nurse-led care meets expected treatment outcomes and is highly safe for patients. In line with these conclusions, our recommendation is that similar studies should be performed in clinics with more complex patient populations.
\end{abstract}

Keywords:Rheumatoid Arthritis, Nursing, Care, Health Care

${ }^{1}$ Öğr. Gör. Dr. Halil İbrahim TUNA, İç Hastalıkları Hemşireliğii, Selçuk Üniversitesi Akşehir Kadir Yallagöz Sağlık Yüksekokulu, tunameister@gmail.com, ORCID: https://orcid.org/0000-0003-2119-5874

${ }^{2}$ Prof. Dr. Özlem ÖRSAL, Halk Sağlığı Hemşireliği, Eskişehir Osmangazi Üniversitesi Sağlık Bilimleri Fakültesi, ozlorsal@gmail.com, ORCID: https://orcid.org/0000-0002-4494- 8587 


\section{GíRIS}

Romatoid artrit (RA) eklem şişliği, eklem hassasiyeti ve sinoviyal eklemlerin tahribi ile karakterize, ağır sakatlık ve mortaliteye yol açan kronik inflamatuar otoimmün bir hastalıktır. $^{1-3}$ RA, dünyadaki en yaygın inflamatuar ağrılı hastalıklardan biridir ve dünya çapında prevalansı $\% 1-2$ arasındadır. ${ }^{4}$

RA'lı hastalar sağlıklı bir kişiye kıyasla fiziksel bozukluklara sahiptir çünkü etkilenen eklemler ağrilı, sert ve deforme olurlar. RA'da ağrı, sertlik, şişmiş eklemler, uykusuzluk, yorgunluk ve hastalığın ilerleyen zamanlarında eklem deformiteleri ortak semptomlardandır. RA vücudun herhangi bir eklemini etkileyebilir. ${ }^{5,6} \mathrm{RA}^{\prime}{ }_{1}$ hastaların yaklaşı $\% 80$ 'i yaşam aktivitelerini sürdürmede zorluklar yaşamaktadır ve \%35'inde ise kalıcı iş göremezlik durumu söz konusudur. ${ }^{4,7}$ RA, kronik hastalık süreci ve oluşturduğu yetersizliklere bağlı hastalığın erken dönemlerinden itibaren hastaların bedensel, ruhsal ve sosyal yönlerini etkileyen bir hastalıktır. ${ }^{9}$ RA'nın tedavisi ilk olarak Hastalık Modifiye Edici Antiromatizmal ilaç (DMARD)'lar ve kortikosteroidler gibi hastalık düzenleyici ajanları içermektedir. İnflamasyon ve ağrı tedavisi, farmakolojik tedavinin ikinci odak noktasıdır. RA'nın yönetimi, hastalık aktivitesini değiştirmeye ve DMARD'ların erken kullanımı yoluyla fiziksel işlevin geliştirilmesine odaklansa da tedavide iltihaplanmanın önlenmesi ve ağrının giderilmesi semptom kontrolü açısından önemlidir. ${ }^{10}$ Hastalığın yönetimi, uzun süreli tedavi gerektirir ve bu da hastaların ve ailelerinin mali yükünü artırır. $^{11}$
Geleneksel olarak tüm RA hastalarının takip edilmesi kliniklerde romatologlar tarafından gerçekleştirilir. Günümüzde romatoloji kliniklerindeki hemşireler, multidisipliner ekibin önemli bir parçası haline gelmektedir ve romatolojik görevleri gerçekleştirebilmektedir. ${ }^{12,13}$ Klinik

romatoloji hemşireleri hastalık aktivitesini değerlendirir, terapinin etkilerini izler, hasta eğitimi, psikolojik destek, bakım koordinasyonu sağlar. ${ }^{14}$ Kliniklerde hemşire odaklı bakım ile hizmet alan hastalar; fiziksel işlev, hastalık aktivitesi, yaşam kalitesi, ağr1, yorgunluk, sertlik, psikolojik işlev ve memnuniyet açısından daha iyi sonuçlar almışlardır. ${ }^{2,12,15}$ Romatoloji hemşiresinin liderliğindeki bakım Kanada, $A B D$ ve Avustralya, Hollanda ve İskandinav ülkelerinde sürdürülmektedir. ${ }^{2,12,15-18}$

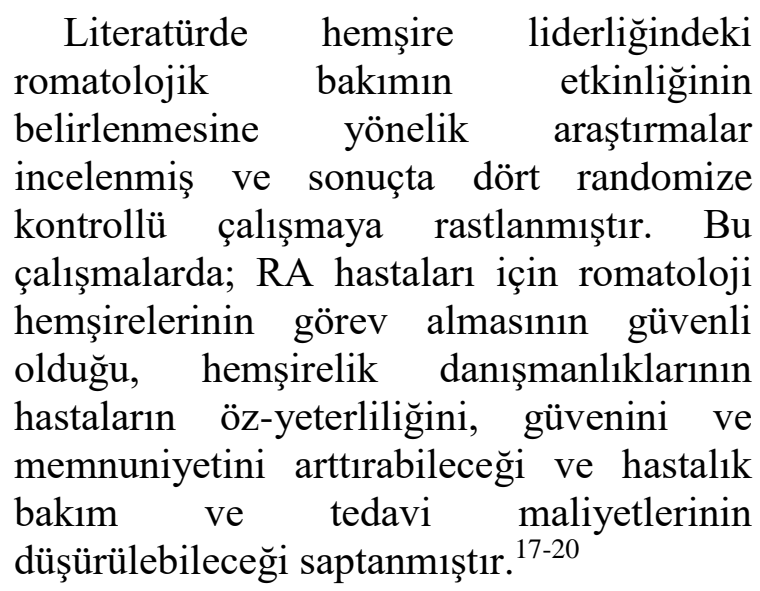

$\mathrm{Bu}$ güncel sistematik derlemenin amacı, romatoid artritli hastalarda hemşirelik liderlikli yönetimin klinik bakımdaki etkinliğinin belirlenmesidir.

\section{MATERYAL VE METOT}

Bu sistematik derleme; York Üniversitesi Ulusal Sağlık Araştırmaları Enstitüsü tarafından geliştirilen rehbere göre yapılmıştır. ${ }^{21}$ Çalışma, konuyla ilgili yayınların geriye dönük olarak taranması biçiminde gerçekleştirilmiştir. Anahtar kelimeler için "Medical Subject Headings"
ve"Türkiye Bilim Terimleri" dizinlerine bakılmıştır. Tarama Selçuk Üniversitesi Kütüphane ağ1 üzerinden gerçekleştirilmiştir. Belirlenen anahtar kelimeler çeşitli kombinasyonlar oluşturularak taranmıştır (Tablo 1). 
Kütüphane ağı üzerinden "romatoid artrit, hemşire ya da hemşirelik, sağlik bakımı" anahtar kelimeleri taranmıştır. Araştırmaya; 2008-2019 yılları arasında Science Direct, PubMed, EBSCO Host, ULAKBIM, Türkiye Atıf Dizini veri tabanlarında yayınlanmış ücretsiz, tam metin makaleler dâhil edilmiştir.

Çalışmaya; Türkçe ve İngilizce dillerinde yapılmış, randomize kontrollü, romatoloji hastalarına bakım verilmiş, hemşirenin doğrudan katkısı olduğu, hemşirelik bakımının değerlendirildiği, sonuçları hemşirelik ile ilişkilendirilebilen tam metin makaleler dâhil edilmiştir. Türkçe ve İngilizce dışındaki dillerde yapılmış çalışmalar ve kongrelerde sunulan sözel ya da poster bildiriler araştırma kapsamına dâhil edilmemiştir.

Tablo 1. Taramada Kullanılan Anahtar Kelimeler

\begin{tabular}{ll}
\hline \multicolumn{1}{c}{ İngilizce } & \multicolumn{1}{c}{ Türkçe } \\
\hline $\begin{array}{l}\text { Rheumatoidarthritis- } \\
\text { nurse- healthcare }\end{array}$ & $\begin{array}{l}\text { Romatoidartrit- } \\
\text { hemşire- } \\
\text { bakımı sağlık }\end{array}$ \\
\hline $\begin{array}{l}\text { Rheumatoidarthritis- } \\
\text { nursing- healthcare }\end{array}$ & $\begin{array}{l}\text { Romatoidartrit- } \\
\text { hemşirelik-sağl1k } \\
\text { bakımı }\end{array}$ \\
\hline
\end{tabular}

Çalıșmaya, makalelerin başlıkları ve özet kısımları incelemeye alınarak başlanmıştır $(n=2048)$. Çalışmanın amacına uygun olan makaleler belirlenmiştir $(\mathrm{n}=246)$. Tekrarlanan makaleler tespit edilip, çıkarılmıştır $(n=126)$. Son olarak; dahil edilme kriterlerine uygun olanlar seçilmiştir $(n=4)$. Araştırma deseni dâhil edilme kriterleri ile uyuşmayan (sistematik derleme/derleme $n=11$ ), dili Türkçe ya da İngilizce olmayan $(\mathrm{n}=4)$, araştırmalar çalışmanın dişında bırakılmıştır. Araştırma süreci Tablo 2'deki gibidir.

Tablo 2. Araştırma Süreci

Taramada Ulaşılan Makale Sayısın= 2048

Science Direct: 1550

EBSCO Host: 331

PubMed: 165

ULAKBİM: 1

Türkiye Atıf Dizini: 1

\begin{tabular}{ll}
\hline İgili olmayan makale sayısı: & 1802 \\
\hline Tekrarlanan makale sayısı: & 126 \\
\hline Sistematik Derleme/ Derleme & 11 \\
\hline $\begin{array}{l}\text { Türkçe-İngilizce dışındaki makale } \\
\text { sayısı: }\end{array}$ & 4 \\
\hline Değerlendirilen makale sayısı: & 105 \\
\hline Dışlanan makale sayısı: & 101 \\
\hline $\begin{array}{l}\text { Araştırmaya dâhil edilen makale } \\
\text { sayısı: }\end{array}$ & 4 \\
\hline
\end{tabular}

\section{MATERYAL VE METOD}

Bu sistematik derlemede dört randomize kontrollü araştırma makalesi incelenmiştir. Araştırmaların ikisi Çin'de, bir tanesi İsveç'te ve bir tanesi de Danimarka'da yapılmıştır. Çalışmalardan elde edilen bulgular "örneklem, amaç/girişim, ölçüm aracı, hemşirelik bakımının etkinliği" şeklinde incelenmiştir (Tablo 2).

\section{Örneklem}

Değerlendirmeye alınan birinci makale Larsson ve ark.'na (2014) aittir. ${ }^{17} \mathrm{Bu}$ araştırmanın örneklemini romatoloji kliniği hastası olan toplam 107 hasta oluşturmuştur ve bu hastalar 53 müdahale grubu 54 hasta da kontrol grubu olarak 2 gruba ayrılmışlardır. Araştırmaya düşük hastalık aktivitesi olan ve biyolojik tedavi gören ve DAS28 $\leq 3.2$ olan hastalar dahil edilmiştir ve katılan hastaların ortama yaşları 55'tir. Değerlendirilmeye alınan ikinci makale Wang ve ark.'na (2018) aittir. ${ }^{19} \mathrm{Bu}$ araştırmanın örneklemini hemşire yönetimine alınan 107 hasta ve hekim yönetimine alınan 107 hasta olmak üzere toplam 214 romatoloji hastas1 oluşturmuştur. Bu araştırmada katılımcıların ortalama yaşı 42.5 'tir. Araştırma 18 yaşından büyük romatoid artrit hastası kadın ve erkekler ile yürütülmüştür. Değerlendirmeye alınan üçüncü makale Wang ve ark.'na (2017) aittir. $^{20} \mathrm{Bu}$ araştırmanın örneklemini 18 yaşından büyük en az bir yıllık RA hastalık tanısı olan 
toplam 220 kadin ve erkek hastalar oluşturmuştur ve bu hastalar 110 hasta hemşire yönetimindeki gruba ve 110 hasta romatolog yönetimindeki gruba dağıtılmıştır. Değerlendirmeye alınan son araştırma Primdahl ve ark. (2013) tarafindan yapılmıştır. ${ }^{18} \mathrm{Bu}$ araştırmanın örneklemini romatoid artrit tanılı sürekli ayaktan tedavi alan ve Hastalık Aktivite Skoru (DAS28CRP) $<3.2$ ve Sağlık Değerlendirme Anketi $<2.5$ olan romatoid artrit hastaları $(n=287)$ oluşturmuştur. Katılımcıların ortalama yaşı 63 'tür. Araştırmaya katılan hastalar 97 hasta romatolog liderlikli grup, 96 hastane paylaşımlı grup ve 94 hemşire liderlikli grup olarak 3 gruba ayrılmıştır.

\section{Amaç/Veri Toplama/Girişim/Sonuç}

Larsson ve ark.'nın (2014) amac1; bir hemşire tarafından yönetilen romatoloji kliniği ile bir romatolog tarafindan yönetilen romatoloji kliniğinde, düşük hastalık aktivitesi olan ve remisyonda olan hastaların tedavi sonuçlarını karşılaştırmaktır. ${ }^{17} \mathrm{Bu}$ araştırmada veriler; Görsel Analog Skala (VAS), Sağlık değerlendirmesi anketi (HAQ) ve Nümerik Değerlendirme Ölçeği kullanılmıştır. Araştırma için hastanın ihtiyaçlarına odaklanan, insan odaklı bakımı temel alan, hemşire yönetimindeki bir romatoloji kliniği tasarlanmıştır. İnsan odaklı bakımın amacı, hastalara kendileri hakkında konuşma firsatı vermek ve akıllarındaki sorulara cevaplar bulabilmek olarak belirtilmiştir. Hastalar altı ay sonra romatoloji hemşiresi tarafindan 30 dakika izlenmiştir. Hemşire romatolog ile aynı şekilde hastalara ait test sonuçlarını, hastalık sebebiyle etkilenmiş eklemleri incelemiştir ve aynı zamanda laboratuar testlerinin sonuçlarını değerlendirmiştir. Bu çalışmanın temel bulgusu, romatolog tarafindan sağlanan tedaviye benzer şekilde romatoloji hemşiresi tarafından takip edilen hastaların da bakımının güvenilir bir şekilde sağlanabilmesi olarak belirtilmiştir.

Wang ve ark.'nın (2018) amacı RA'lı hastalarda romatoloji hekimine karş1 hemşire liderliğindeki klinik bakımın etkinliği ve maliyet etkinliğini değerlendirmektir. ${ }^{19}$ VAS, sabah tutukluluk ve sertlik süresi kayıt skalası ve kaynak kullanım anketi ile toplanmıştır. Kaynak kullanım anketi şu maddelerle ilişkilidir: sağlık çalışanlarıyla temaslar, hastane başvuruları, RA enjeksiyonları ve RA ile ilgili testler ve prosedürler, artritle ilgili reçeteli ilaçlar özellikle biyolojik ve biyolojik olmayan ilaçlar, antiromatizmal ilaçlar, opioid analjezikler, artrit nedeniyle çalışma zamanı; sağlık profesyonelleri ile iletişim ile ilişkili seyahat masrafları olarak belirtilmiştir. $\mathrm{Bu}$ çalışmada klinik hemşire uzmanı öykü almış, fizik muayene yapmış, hastalık şiddetini değerlendirmiş, reçete edilen veya önerilen ilaç ve dozaj değişimlerini ve reçete edilen anti-RA ilaçlarının etkilerini izlemiş, hastalarını eğitmiş, reçeteli ilaçların doğru kullanımı konusunda talimat vermiş ve psikososyal destek sağlamıștır. Hekim kendi tedavi rutinine devam etmiştir. Hastalar 3, 6, 9 ve 12. aylarda izlenmiştir. Araştırma sonucunda hemşire yönetimindeki bakımın romatoloji hekimine göre, daha iyi klinik sonuçlar ve az maliyetli olduğu sonucuna ulaşılmıştır. ${ }^{19}$

Wang ve ark.'nın (2017) yaptığı benzer bir diğer araştırmanın amac1, hemşire liderliğinde bakım kavramının RA'lı Çin'li hastalarda romatolog tarafindan yönlendirilen bakımdan daha yüksek hasta memnuniyeti ile ilişkili olup olmadığını kontrol etmektir. $\mathrm{Bu}$ araştırmada veri toplamak için Leeds Memnuniyet Anketi (LSKS) 12 aylik süre boyunca her konsültasyon öncesi ve sonrasi DAS 28 skoru, ağr1, yorgunluk ve sabah tutukluğu için VAS kullanılmıştır. ${ }^{20}$ Klinik uzman hemşire hastaların, tıbbi ve hastalık öyküsünü almıştır, hastalığın şiddetini değerlendirmiştir ve reçete edilen anti-RA ilaçlarının etkilerini izlemiştir. Hemşire gerektiğinde röntgen istemi de dahil olmak üzere doğru laboratuvar araştırmalarına rehberlik etmiştir. Gerekirse, hastaları romatolog veya başka bir sağlık bakım uzmanına yönlendirmiştir. Romatolog kendi tedavi rutinine devam etmiştir. $\mathrm{Bu}$ çalışmanın sonucunda hemşire liderliğinde 
bakım alan RA hastalarının hasta memnuniyeti anlamlı düzeyde yüksek bulunmuştur ve romatolog tarafindan verilen bakıma göre hastalık semptomlarında anlamlı iyileşme olduğu saptanmıştır. ${ }^{20}$

Primdahl ve ark.'nın (2013) yaptığ1 araştırmanın amacı, sürekli düşük aktif RA'lı ve ayaktan tedavi alan hastalara romatologlarla yapılan geleneksel takiplerle alternatif bakım rejimlerinde hasta sonuçlarını karşılaştırmaktır. Hipotez; planlanmış konsültasyonlar ve deneyimli romatoloji hemşireleri tarafindan planlanan, klinik sonuçları iyileştiren ve yaşam kalitesini yükselten bir bakım modeli uygulayabilmek ve katılımcıların özetkililiğini, güven ve memnuniyet düzeyinin arttırmaktır. ${ }^{18} \mathrm{Bu}$ araştırmada veriler Sağlık Değerlendirme Anketi, VAS, RA Özyeterlik anketi ve Artrit Öz-Yetkinlik Ölçeği ile toplanmıştır. Romatolog grubundaki kat1lımc1lar her 3-12 ayda bir 30-60 dakikalık konsültasyonla takip edilmeye devam etmişlerdir. Hemşire grubundaki katılımcılar, klinik olarak deneyimli romatoloji polikliniğinde 3 ayda bir planlanmış 30 dakikalık görüşmelere ayrılmıştır. $\mathrm{Bu}$ katılımcılar ayrıca, hemşireye telefonla ulaşabilmişlerdir. $\mathrm{Bu}$ çalışma, düşük aktif RA'lı hastalar için deneyimli romatoloji hemşirelerinin takip bakımı yapmalarına izin vermenin güvenli olduğunu göstermiştir. Hemşirelerin takip bakımına dâhil edilmesi, hastaların özyeterlik inançlarını artırma potansiyelleri ve takipli bakımları ile ilgili güven ve memnuniyetini arttırmıştır. ${ }^{18}$ 


\section{Tablo 3. Makaleler ve İcerikleri}

\begin{tabular}{|c|c|c|c|c|c|c|c|c|}
\hline & Yazar- Yıl & $\begin{array}{l}\text { Araştırmanın Adı/ } \\
\text { Türü }\end{array}$ & $\begin{array}{l}\text { Araştırmanın } \\
\text { amacı }\end{array}$ & Örneklem & $\begin{array}{l}\text { Çalışma } \\
\text { grubu }\end{array}$ & $\begin{array}{l}\text { Veri } \\
\text { Toplamada } \\
\text { Kullanılan } \\
\text { Yöntem }\end{array}$ & Protokol & Sonuç \\
\hline 1 & $\begin{array}{l}\text { Larsson, } \\
\text { I.,Fridlund } \\
\text {, B., } \\
\text { Arvidsson, } \\
\text { B., } \\
\text { Teleman, } \\
\text { A., } \\
\text { \&Bergman } \\
\text {, S. } \\
(2014)\end{array}$ & $\begin{array}{l}\text { Romatoloji } \\
\text { Kliniğinde } \\
\text { Biyolojik Tedavinin } \\
\text { Hemşire } \\
\text { Liderliğinde } \\
\text { İzlenmesi } \\
\text { Randomize } \\
\text { Kontrollü }\end{array}$ & $\begin{array}{l}\text { Hemşire tarafindan } \\
\text { yönetilen } \\
\text { romatoloji kliniği } \\
\text { ve romatolog } \\
\text { tarafından yönetilen } \\
\text { bir klinikte } \\
\text { remisyonda olan } \\
\text { düşük hastalık } \\
\text { aktivitesi olan veya } \\
\text { biyolojik tedavi } \\
\text { gören hastaların } \\
\text { bakım sonuçlarını } \\
\text { karşılaştırmak }\end{array}$ & $\begin{array}{l}\mathrm{n}=107 \\
53 \text { hasta } \\
\text { müdahale } \\
54 \text { hasta } \\
\text { kontrol }\end{array}$ & $\begin{array}{l}\text { Düşük } \\
\text { hastalık } \\
\text { aktivitesi } \\
\text { olan, } \\
\text { biyolojik } \\
\text { tedavi } \\
\text { gören ve } \\
\text { DAS28 } \\
\leq 3.2 \text { olan } \\
\text { hastalar }\end{array}$ & $\begin{array}{l}\text { VAS, } \\
\text { HAQ, } \\
\text { NRS }\end{array}$ & $\begin{array}{l}\text { Hastanın ihtiyaçlarına odaklanan, } \\
\text { insan odaklı bakımı temel alan, } \\
\text { hemşire liderliğindeki romatoloji } \\
\text { kliniği tasarlanmıştır. Hastalar } 6 \\
\text { ay sonra romatoloji hemşiresi } \\
\text { tarafından } 30 \text { dakika izlenmiştir. } \\
12 \text { ay sonra romatolog tarafından } \\
30 \text { dakika izlenmiştir. Hemşire } \\
\text { romatolog ile aynı şekilde, } \\
\text { hastalara ait test sonuçlarını, } \\
\text { eklemleri incelemiş ve aynı } \\
\text { zamanda laboratuar testlerinin } \\
\text { sonuçlarını değerlendirmiştir. }\end{array}$ & $\begin{array}{l}\text { Bu çalışmanın temel } \\
\text { bulgusu, romatolojist } \\
\text { tarafından sağlanan } \\
\text { tedaviye benzer bir etkinlik } \\
\text { ile romatoloji hemşiresi } \\
\text { tarafından takip edilen } \\
\text { bakımın güvenilir bir } \\
\text { şekilde sağlandığ } 1 \\
\text { sonucuna ulaşılmıştır. }\end{array}$ \\
\hline 2 & $\begin{array}{l}\text { Wang, } \\
\text { J.,Zou, X., } \\
\text { Cong, L., } \\
\text { \&Liu, H. } \\
(2018) .\end{array}$ & $\begin{array}{l}\text { Romatoid Artritli } \\
\text { Çinli Hastalarda } \\
\text { Hemşire } \\
\text { Liderliğindeki } \\
\text { Bakımın Klinik } \\
\text { Etkinliği ve Maliyet } \\
\text { Etkinliği: } \\
\text { Romatolog } \\
\text { Liderliğindeki } \\
\text { Bakım ile } \\
\text { Karşılaştırılan Bir } \\
\text { Çalışma } \\
\text { Randomize } \\
\text { kontrollü }\end{array}$ & $\begin{array}{l}\text { RA' lı Çinli } \\
\text { hastalarda } \\
\text { romatolog ile } \\
\text { hemşire } \\
\text { liderliğindeki } \\
\text { bakımın etkinliği ve } \\
\text { maliyet etkinliğini } \\
\text { karşılaştırmaktır. }\end{array}$ & $\begin{array}{l}\mathrm{n}=214 \\
\text { Hemşire } \\
\text { liderlikli grup: } \\
107 \\
\text { Hekim grubu: } \\
107\end{array}$ & $\begin{array}{l}1 \text { yıldan } \\
\text { uzun süreli } \\
\text { RA } \\
\text { hastalık } \\
\text { tanısı } \\
\text { onlalar ve } \\
18 \\
\text { yaşından } \\
\text { büyük } \\
\text { hastalar }\end{array}$ & $\begin{array}{l}\text { Kaynak } \\
\text { kullanım } \\
\text { anketi, } \\
\text { VAS, } \\
\text { Sabah } \\
\text { Tutukluluk ve } \\
\text { Sertlik Kayıt } \\
\text { Ölçeği }\end{array}$ & $\begin{array}{l}\text { Hemşire; öykü almış, fizik } \\
\text { muayene yapmış, hastalık } \\
\text { şiddetini değerlendirmiş, reçete } \\
\text { edilen veya önerilen ilaç ve dozaj } \\
\text { değişimleri, reçete edilen anti- } \\
\text { RA ilaçlarının etkilerini izlemiş, } \\
\text { hastalarını eğitmiş, reçeteli } \\
\text { ilaçların doğru kullanımı } \\
\text { konusunda eğitim vermiş ve } \\
\text { psikososyal destek sağlamıştır. } \\
\text { Hastalarla 3., } 6 ., 9 ., \text { ve } 12 \text {. } \\
\text { aylarda görüşülmüştür. }\end{array}$ & $\begin{array}{l}\text { Hemşire liderliğindeki } \\
\text { bakımın romatoloğa göre } \\
\text { daha iyi klinik sonuçlar ve } \\
\text { az maliyetli olduğu } \\
\text { sonucuna ulaşılmıştır. }\end{array}$ \\
\hline
\end{tabular}




\begin{tabular}{|c|c|c|c|c|c|c|c|c|}
\hline \multicolumn{3}{|c|}{$\begin{array}{l}\text { GÜSBD 2021; 10(1): 144-152 } \\
\text { GUJHS 2021; 10(1): 144-152 }\end{array}$} & \multicolumn{2}{|c|}{$\begin{array}{l}\text { Gümüşhane Üniversitesi Sağllk Bilimleri Dergisi } \\
\text { Gümüşhane University Journal of Health Sciences }\end{array}$} & \multicolumn{4}{|c|}{$\begin{array}{r}\text { Derleme } \\
\text { Review } \\
\end{array}$} \\
\hline 3 & $\begin{array}{l}\text { Wang, } \\
\text { J.,Zou, X., } \\
\text { Zhou, L., } \\
\text { \&Liu, H. } \\
\text { (2017) }\end{array}$ & $\begin{array}{l}\text { Romatoid Artritli } \\
\text { Çinli Hastalarda } \\
\text { Hemşire } \\
\text { Liderliğindeki } \\
\text { Bakımdan Sonra } \\
\text { Hasta } \\
\text { Memnuniyeti. } \\
\text { Randomize } \\
\text { kontrollü }\end{array}$ & $\begin{array}{l}\text { RA' li hastalarda } \\
\text { hemşirelik } \\
\text { bakımının hasta } \\
\text { memnuniyetine } \\
\text { etkisine bakmaktır. } \\
\text { Çalışmanın birincil } \\
\text { amacı, hastaların } \\
\text { memnuniyetini } \\
\text { değerlendirmektir. } \\
\text { Çalışmanın ikincil } \\
\text { amacı, DAS 28, } \\
\text { ağrı, yorgunluk ve } \\
\text { sabah tutukluğunu } \\
\text { ölçmektir. }\end{array}$ & $\begin{array}{l}\mathrm{n}=220 \\
110 \text { hasta } \\
\text { hemşire } \\
\text { liderliğinde } \\
110 \text { hasta } \\
\text { romatolog } \\
\text { liderliğinde }\end{array}$ & $\begin{array}{l}18 \\
\text { yaşından } \\
\text { büyük ve } \\
\text { en az } 1 \\
\text { y1llik } \\
\text { romatoid } \\
\text { artrit tanıs1 } \\
\text { olan } \\
\text { hastalar }\end{array}$ & $\begin{array}{l}\text { LSKS, } \\
12 \text { aylık süre } \\
\text { boyunca her } \\
\text { konsültasyon } \\
\text { öncesi ve } \\
\text { sonrası DAS } \\
28 \text { skoru, ağrı, } \\
\text { yorgunluk ve } \\
\text { sabah } \\
\text { tutukluğu için } \\
\text { VAS } \\
\text { kullanılmıştır. }\end{array}$ & $\begin{array}{l}\text { Romatoloji hemşiresi hastalık } \\
\text { öyküsünü kaydetmiş, fizik } \\
\text { muayene yapmış, hastalığın } \\
\text { şiddetini değerlendirmiş ve reçete } \\
\text { edilen anti-RA ilaçlarının } \\
\text { etkilerini izlemiştir. Hemşire } \\
\text { laboratuvar araştırmalarına } \\
\text { rehberlik etmiştir. Gerekirse, } \\
\text { hastaları romatolog veya başka } \\
\text { bir sağlı bakım uzmanına } \\
\text { yönlendirmiştir. } \\
\begin{array}{l}\text { Romatolog rutinine devam } \\
\text { etmiştir. }\end{array}\end{array}$ & $\begin{array}{l}\text { Hemşirelik bakımı alan RA } \\
\text { hastalarının hasta } \\
\text { memnuniyeti daha yüksek } \\
\text { bulunmuştur ve romatolog } \\
\text { tarafından verilen bakıma } \\
\text { göre hastalık } \\
\text { semptomlarında iyileşme } \\
\text { olduğu saptanmıştır. }\end{array}$ \\
\hline 4 & $\begin{array}{l}\text { Primdahl, } \\
\text { J.,Sørense } \\
\text { n, J., Horn, } \\
\text { H. C., } \\
\text { Petersen, } \\
\text { R., } \\
\text { \&Hørslev- } \\
\text { Petersen, } \\
\text { K. } \\
(2013)\end{array}$ & $\begin{array}{l}\text { Romatoloji } \\
\text { Kliniğinde Düşük } \\
\text { Hastalık Aktivitesi } \\
\text { Olan Hastaların } \\
\text { Romatolog } \\
\text { Takibine } \\
\text { Olarak rernatif } \\
\text { Bakım Verilen } \\
\text { Hemşirelik veya } \\
\text { Konsültasyonları. } \\
\text { Randomize } \\
\text { kontrollü }\end{array}$ & $\begin{array}{l}\text { Düşük hastalık } \\
\text { aktivitesi olan RA'lı } \\
\text { ayaktan takip edilen } \\
\text { hastalara } \\
\text { romatologlarla } \\
\text { yapılan geleneksel } \\
\text { takiplerle } \\
\text { hemşirelik } \\
\text { bakımının hasta } \\
\text { sonuçlarına } \\
\text { etkisinin } \\
\text { karşıllaştırmaktır. } \\
\text { Ayrıca } \\
\text { katılımcıların öz- } \\
\text { etkililiğinin, güven } \\
\text { ve memnuniyet } \\
\text { düzeyinin } \\
\text { arttırılmasıdır. }\end{array}$ & $\begin{array}{l}\mathrm{n}=191 \\
97 \text { hasta } \\
\text { romatolog } \\
94 \text { hasta } \\
\text { hemşirelik }\end{array}$ & $\begin{array}{l}\text { RA tanılı } \\
\text { ayaktan } \\
\text { tedavi alan } \\
\text { hastalar. }\end{array}$ & $\begin{array}{l}\text { Sağlık } \\
\text { Değerlendirme } \\
\text { Anketi, } \\
\text { VAS, } \\
\text { yorgunluk, } \\
\text { yaşam kalitesi } \\
\text { ve RA Öz- } \\
\text { yeterlik anketi, } \\
\text { Artrit Öz- } \\
\text { Yetkinlik } \\
\text { Ölçeği. }\end{array}$ & $\begin{array}{l}\text { Romatolog grubundaki } \\
\text { katılımcılar bir hekim tarafindan } \\
3-12 \text { ayda bir, 30-12 dakikalık } \\
\text { görüşmeyle takip edilmiştir. } \\
\text { Hemşire grubundaki katılımcılar } \\
\text { ile3 ayda bir 30 dakikalık } \\
\text { görüşmeler yapılmıştır. } \\
\text { Bu katılımcılara ayrıca, } \\
\text { hemşireye telefonla ulaşma } \\
\text { imkânı sağlanmıştır }\end{array}$ & $\begin{array}{l}\text { Bu çalışma, düşük aktif } \\
\text { RA'lı hastalar için } \\
\text { deneyimli romatoloji } \\
\text { hemşirelerinin sıkı takip } \\
\text { bakımı yapmalarına izin } \\
\text { vermenin güvenli olduğunu } \\
\text { göstermiştir. Hemşirelerin } \\
\text { takip bakımına dahil } \\
\text { edilmesi, hastaların öz- } \\
\text { yeterliklerini, güven ve } \\
\text { memnuniyetini arttırmıştır. }\end{array}$ \\
\hline
\end{tabular}


Hemşire önderliğindeki diyabet, enfeksiyon, kardiyovasküler, diyaliz gibi birimler hekim liderliğindeki kliniklerin tamamlayıcısı olarak kurulmuştur. ${ }^{22-}$ ${ }^{25}$ Hastalar, hemşirenin yönlendirdiği kliniklerde daha iyi bakım memnuniyeti yaşamaktadır. Literatürde kardiyak problemi olan, kanser, diyabet hastası hastalar üzerine yapılmış çalışma sonuçları da hemşire liderliğindeki bakımın etkinliğini bildirmektedir. ${ }^{26-29}$ RA'da bakım kalitesini arttırmak için hemşirelerin aktif olduğu romatoloji klinikleri önerilmiştir. ${ }^{30,31} \mathrm{Bu}$ derlemede incelenen makaleler, RA'l1 hastalara hemşire yönetiminde verilen bakımın hasta memnuniyetini arttırdığını, maliyet açısından etkin olduğunu, hastaların yaşam kalitelerini yükselttiğini ve tedaviden maksimum fayda sağlandığını bildirmektedir.

\section{SONUÇ VE ÖNERILER}

Hemşirelerin RA bakımında lider rol alması hastaların öz-yeterliklerini, bakım memnuniyetini arttırmaktadır ve tedavi maliyetini azaltmaktadır. Hemşire liderlikli bakım, beklenen tedavi sonuçlarını karşılamaktadır ve hastalar için oldukça güvenlidir. Hemşire liderliğindeki romatoloji kliniği müdahalesi, hastaların bakımında güvenli bir uygulama olabileceği bu sistematik derlemede incelenen makalelerin sonuçlarındandır. Ek olarak bir hemşire tarafından bakım alan RA hastalarının önemli ölçüde daha yüksek hasta memnuniyetine sahip olduğu ve romatolog liderliğindeki bakıma göre hastalık semptomların da önemli ölçüde daha fazla iyileșme gösterdiği dikkat çeken bir sonuçtur. $\mathrm{Bu}$ sonuçlar doğrultusunda önerimiz romatoloji hastalarının tedavi ve bakım yönetimine romatoloji hemşirelerinin de dâhil olması ve hemşire liderliğinde verilen bakımın kalitesini göstermeye yönelik yeni güncel araştırmaların yapılmasıdır.

\section{KAYNAKLAR}

1. Aletaha, D, Neogi, T, Silman, A.J, Funovits J, Felson, D.T, Bingham, C.O. et al. (2010). "Rheumatoid Arthritis Classification Criteria: An American College of Rheumatology/European League Against Rheumatism Collaborative Initiative". Arthritis \& Rheumatology, 62 (9), 2569-2581. doi: 10.1002/art.27584

2. Ndosi, M, Vinall, K, Hale, C, Bird, H. and Hill, J. (2011). "The Effectiveness of Nurse-Led Care in People with Rheumatoid Arthritis: A Systematic Review." International Journal of Nursing Studies, 48 (5), 642-654. doi: 10.1016/j.ijnurstu.2011.02. 007

3. Smolen, J.S. and Steiner, G. (2003). "Therapeutic Strategies for Rheumatoid Arthritis". Nature Reviews Drug Discovery, 2 (6), 473. doi: $10.1038 / \mathrm{nrd} 1109$

4. Wasserman, A.M. (2011)."Diagnosis And Management of Rheumatoid Arthritis". American Family Physician, 84 (11), 1245.

5. Combe, B. (2007). "Early Rheumatoid Arthritis: Strategies for Prevention And Management". Best Practice \& Research Clinical Rheumatology, 21 (1), 27-42. doi: 10.1016/j.berh. 2006. 08.011

6. Steultjens, E, Dekker, J, Bouter, M, Schaardenburg, D. and Kuyk, M. (2004). "Occupational Therapy for Rheumatoid Arthritis". The Cochrane Library, 4. doi: 10.1002/14651858. CD00 3114.pub2

7. Allaire, S, Wolfe, F, Niu, J, LaValley, M.P, Zhang, B. and Reisine, S. (2009). "Current Risk Factors for Work Disability Associated With Rheumatoid Arthritis: Recent Data from A US
National Cohort". Arthritis Care \& Research, 61 (3), 321328. doi: 10.1002/art. 24281

8. Choy, E.H. and Panayi, G.S. (2001). "Cytokine Pathways and Joint Inflammation in Rheumatoid Arthritis". New England Journal of Medicine, 344 (12), 907-916. doi 10.1056/NEJM200103223441207

9. Salaffi, F, Carotti, M, Gasparini, S, Intorcia, M. and Grassi, W (2009). "The Health-Related Quality of Life in Rheumatoid Arthritis, Ankylosing Spondylitis, and Psoriatic Arthritis: A Comparison with A Selected Sample of Healthy People". Health and Quality of Life Outcomes, 7 (1), 25. doi:10.1186/ 1477-7525-7-25

10. Kwoh, C.K, Anderson L.G, Greene J.M, Johnson, D.A, O’Dell, J.R, Robbins, M.L, Roberts, W.N, Simms, R.W. and Yood, R.A. (2002). "American College of Rheumatology Subcommittee on Rheumatoid Arthritis Guidelines". Arthritis and Rheumatology, 46 (2), 328-346.

11. Curtis, J.R, Patkar, N, Xie, A, Martin, C, Allison, J.J, Saag, M. et al. (2007). "Risk of Serious Bacterial Infections among Rheumatoid Arthritis Patients Exposed to Tumor Necrosis Factor a Antagonists". Arthritis and Rheumatology, 56 (4), 1125-1133. doi: 10.1002/art.22504

12. Hill, J. (2007). "Rheumatology Nurse Specialists-Do We Need Them?". Oxford University Press, 46 (3), 379. doi: 10.1093/ rheumatology/kel431

13. Van Eijk-Hustings, Y, Van Tubergen, A, Boström, C, Braychenko, E, Buss, B. Felix, J. et al. (2011). "EULAR Recommendations for The Role of The Nurse in The Management of Chronic Inflammatory Arthritis". Annals of 
The Rheumatic Diseases, 200185. doi: 10.1136/annrheumdis2011-200185

14. Watts, R.A, Mooney, J, Barton, G, MacGregor, A.J, Shepstone, L, Irvine, L. et al. (2015). "The Outcome And CostEffectiveness of Nurse-Led Care in The Community for People with Rheumatoid Arthritis: A Non-Randomised Pragmatic Study". BMJ Open, 5 (8), 76-96. doi: 10.1136/bmjopen-2015007696

15. Tijhuis, G.J, Zwinderman, A.H, Hazes, J.M, Breedveld, F.C. and Vlieland, P. (2003). "Two-Year Follow-Up of A Randomized Controlled Trial of A Clinical Nurse Specialist Intervention, Inpatient, and Day Patient Team Care in Rheumatoid Arthritis". Journal of Advanced Nursing, 41 (1), 34-43. doi: 10.1046/j.1365-2648.2003.02503.x

16. Koksvik, H.S, Hagen, K.B, Rødevand, E, Mowinckel, P, Kvien, T.K. and Zangi, H.A. (2012). "Patient Satisfaction with Nursing Consultations in A Rheumatology Outpatient Clinic: A 21Month Randomised Controlled Trial in Patients With Inflammatory Arthritides". Annals of The Rheumatic Diseases, 202-296. doi: 10.1136/annrheumdis-202296

17. Larsson, I, Fridlund, B, Arvidsson, B, Teleman, A. and Bergman, S. (2014). "Randomized Controlled Trial of A NurseLed Rheumatology Clinic for Monitoring Biological Therapy". Journal of Advanced Nursing, 70 (1), 164-175. doi: 10.1111/jan.12183

18. Primdahl, J, Sørensen, J, Horn, H.C, Petersen, R. and HørslevPetersen, K. (2012). "Shared Care Or Nursing Consultations As An Alternative to Rheumatologist Follow-Up for Rheumatoid Arthritis Outpatients With Low Disease Activity-Patient Outcomes from A 2-Year, Randomised Controlled Trial". Annals of the Rheumatic Diseases, 202-695. doi: 10.1136/annrheum dis-2012-202695

19. Wang, J, Zou, X. ve Cong, L. and Liu, H. (2018). "Clinical Effectiveness And Cost-Effectiveness of Nurse-Led Care in Chinese Patients With Rheumatoid Arthritis: A randomized Trial Comparing with Rheumatologist-Led Care". International Journal of Nursing Practice, 24 (1), 12605. doi: 10.1111/ijn. 12605

20. Wang, J, Zou, X, Zhou, L. and Liu, H. (2017). "Patient Satisfaction After Nurse-Led Care in Chinese Patients with Rheumatoid Arthritis: A China Study”. Biomedical Research, 28 (11), 4972-4978.

21. Dixon-Woods, M, Bonas, S, Booth, A, Jones, D.R, Miller, T, Sutton, A.J. et al. (2006). "How Can Systematic Reviews
Incorporate Qualitative Research? A Critical Perspective". Qualitative Research, 6 (1), 27-44. doi: 10.1177/14687941060 58867

22. Chin, W, Lam, C.L. and Lo, S. (2011). "Quality of Care of Nurse-Led and Allied Health Personnel-Led Primary Care Clinics”. Hong Kong Medical Journal, 17 (3), 217.

23. Cooper, J.M, Loeb, S.J. and Smith, C.A. (2010). "The Primary Care Nurse Practitioner And Cancer Survivorship Care”. Journal of the American Academy of Nurse Practitioners, 22 (8), 394-402. doi: 10.1111/j.1745-7599.2010.00528.x

24. Kirby, M. (2005). "Extending Nursing Roles in Diabetes to Achieve Clinical Targets”. Journal of Diabetes Nursing, 9 (6) 231-236.

25. Strömberg, A, Mårtensson, J, Fridlund, B. and Dahlström, U. (2001). "Nurse-Led Heart Failure Clinics in Sweden". European Journal of Heart Failure, 3 (1), 139-144. doi: 10.1016/S1388-9842(00)00099-4

26. Clark, C.E, Smith, L.F, Taylor, R.S. and Campbell, J.L. (2010). "Nurse Led Interventions to Improve Control of Blood Pressure in People with Hypertension: Systematic Review and MetaAnalysis". BMJ, 341, c3995. doi: 10.1136/bmj. c3995

27. Lewis, R, Neal, R.D, Williams, N.H, France, B, Wilkinson, C, Hendry, M. et al. (2009). "Nurse-led vs. Conventional Physician-Led Follow-Up for Patients with Cancer: Systematic Review". Journal of Advanced Nursing, 65 (4), 706-723. doi: 10.1111/j. 1365-2648.2008.04927.x

28. Schadewaldt, V. and Schultz, T. (2011). "Nurse-Led Clinics As An Effective Service For Cardiac Patients: Results from A Systematic Review". International Journal of Evidence-Based Healthcare, 9 (3), 199-214. doi: 10.1111/j.17441609.2011.00217.x

29. Wong, F.K.Y, Mok, M.P.H, Chan, T. and Tsang, M.W. (2005) "Nurse Follow-Up of Patients With Diabetes: Randomized Controlled Trial". Journal of Advanced Nursing, 50 (4), 391 402. doi: 10.1111/j.1365-2648.2005.03404.x

30. Oliver, S.M. (2011). "The Role of The Clinical Nurse Specialist in The Assessment and Management of Biologic Therapies". Musculoskeletal Care, 9 (1), 54-62. doi: 10.1002/msc. 190

31. Palmer, D. and Miedany Y.E. (2010). "Biological Nurse Specialist: Goodwill to Good Practice". British Journal of Nursing, 19 (8), 477-448. doi: 10.12968/bjon.2010.19.8.47632 